\title{
Precision Medicine Oncology
}





\title{
Precision Medicine Oncology
}

\author{
A PRIMER
}

\section{Edited by}

\section{Lorna Rodriguez-Rodriguez, MD}

Director of Precision Medicine

Professor of Obstetrics/Gynecology and Reproductive Services

Robert Wood Johnson Medical School

Chief of Gynecologic Oncology

Rutgers Cancer Institute of New Jersey

New Brunswick, NJ

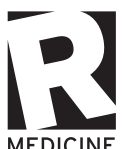

MEDICINE

\section{Rutgers University Press}

New Brunswick, Camden, and Newark, New Jersey, and London 
Library of Congress Cataloging-in-Publication Data

Names: Rodriguez-Rodriguez, Lorna, editor.

Title: Precision medicine oncology : a primer / edited by Lorna

Rodriguez-Rodriguez.

Description: New Brunswick, New Jersey : Rutgers University

Press, [2020] | Includes bibliographical references and index. Identifiers: LCCN 2018053057 | ISBN 9780813575872

(cloth : alk. paper) | ISBN 9780813575896 (web pdf)| ISBN 9781978807082 (mobi) | ISBN 9780813575889 (epub)

Subjects: | MESH: Neoplasms-therapy | Precision Medicinemethods | Medical Oncology_methods | Genetic Techniques | Clinical Trials as Topic

Classification: LCC RC263 | NLM QZ 266 | DDC 616.99/4-dc23 LC record available at https://lccn.loc.gov/2018053057

A British Cataloging-in-Publication record for this book is available from the British Library.

This collection copyright (C) 2019 by Rutgers, The State University of New Jersey

Individual chapters copyright (C) 2019 in the names of their authors

All rights reserved

No part of this book may be reproduced or utilized in any form or by any means, electronic or mechanical, or by any information storage and retrieval system, without written permission from the publisher. Please contact Rutgers University Press, 106 Somerset Street, New Brunswick, NJ 08901. The only exception to this prohibition is "fair use" as defined by U.S. copyright law.

(2) The paper used in this publication meets the requirements of the American National Standard for Information SciencesPermanence of Paper for Printed Library Materials, ANSI Z39.48-1992.

www.rutgersuniversitypress.org

Manufactured in the United States of America 
This book is dedicated to all the patients who have generously and enthusiastically participated in clinical trials at the Rutgers Cancer Institute of New Jersey. They are our constant inspiration and motivation to continue our research and our partnership in finding cures. I would like to specifically mention Ms Dorinda Sparacio (Dee), who, after being treated in a clinical trial at the Cancer Institute of New Jersey, is cancer free for over 10 years and now partners with us as a wonderful patient advocate. Thanks for keeping us going, Dee! I also want to thank a young woman, Rachael M. McCleery, who was enrolled in the Precision Medicine Oncology clinical trial, battled with us, and benefited for a while from targeted therapy. Her smile and optimism filled the hearts of the Precision Medicine Oncology team and encouraged us to share our knowledge through this book. Finally, this review is also dedicated to Rita Kay Thomas, who participated in clinical trials and posthumously continues to contribute to research thanks to continuous donations made by her life partner, Kathleen Wurster. 
